\title{
Retrospective analysis of urban development in the Spanish Mediterranean coast
}

\author{
S. García-Ayllón \\ Department of Civil Engineering, \\ Technical University of Cartagena, Spain
}

\begin{abstract}
Spain's economic development is strongly influenced by an important urban growth on the coast for the past 50 years. This fact is associated with economic cycles and especially with the emergence of mass tourism. This phenomenon, marked by a strong seasonality, generates considerable controversy in urban and infrastructures planning. Resource consumption, land transformation and service management are variables to study to assess the development of the Spanish coast. It is necessary to introduce new systems of control and observation in the evolution of urban space towards ensuring the sustainability and competitiveness of our cities. The application of spatial information technologies to traditional governance methods is in this sense a future strategic commitment. This methodology is currently being investigated in the European Union. This paper takes a retrospective analysis of the evolution of the coastal development in the Mediterranean through the use of GIS tools and spatial information systems implemented in recent European research projects as OSDDT, Otremed and Pays-Med-Urban.

Keywords: land transformation, territorial policies, Mediterranean planning, tourism development, coastal developmentalism, soil consumption, Mazarron coastline.
\end{abstract}

\section{Introduction}

The coastline has become in the Mediterranean Europe a major economic asset. Countries like Italy, Spain and France are on the top of the world in number of visitors whose main destination is usually the Mediterranean coast. 
In Spain, it currently has been consolidated a coastal model of land occupation. In 2010, even if this territory represented only $7 \%$ of the country's area, more than $44 \%$ of the total population lived in coastal municipalities. Among the 46.2 million of foreign tourists coming into the country that year, $87.2 \%$ chose the coast for their holidays. This implies an average of 5,860 tourists per $\mathrm{km}$ of coastline [1]. However, this distribution is very asymmetric, being at the same time very differentiated its impact depending on the area, in cases such as the Mediterranean coast (Fig. 1).

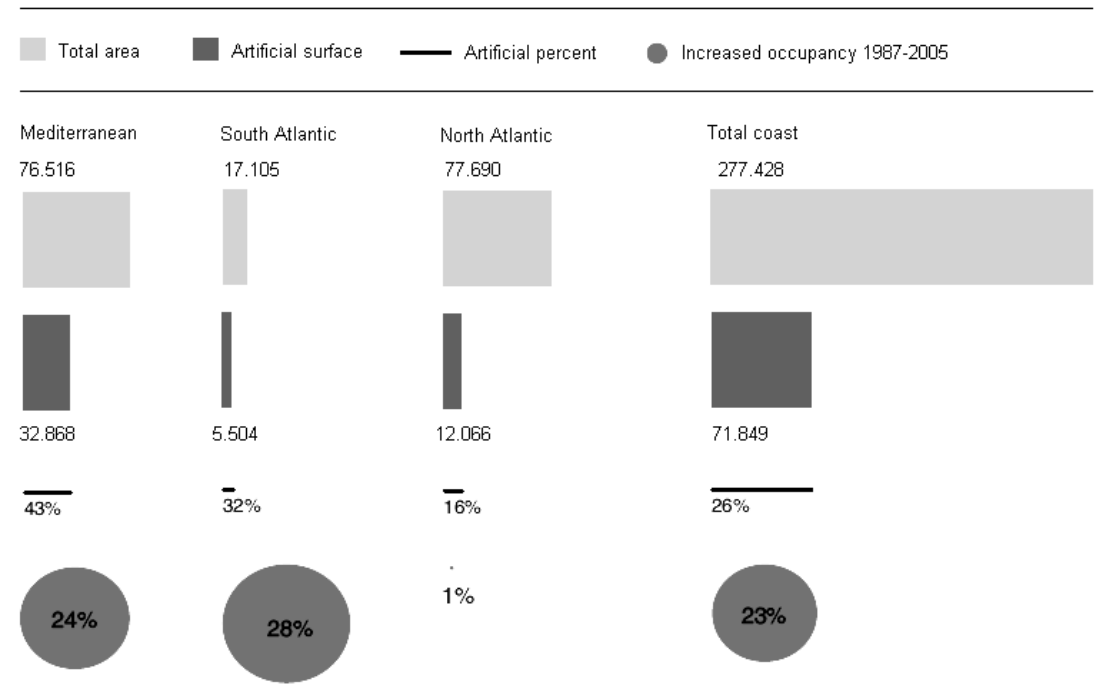

Figure 1: Distribution of land transformation in the Spanish coast (source: [1]).

This stretch of occupation is mainly concentrated in the first kilometer of coastline. In fact, between 1987 and 2005 the artificial surface in the first 500 meters of coastline grew significantly in almost the entire Spanish coastline. Starting from the range of 500 meters, construction moved inland, though with less intensity, to increasingly remote areas of the coastline (resort phenomenon).

In the first 500 meters of coastline coexist various uses. However, the most important are certainly those related to activities resulting from urban growth. This growth occurs continuously in the urban plot of the cities, but especially through poorly controlled urban sprawl phenomena (Fig. 2).

The artificialization of soil has reached on average in Spain, 26\% in the first 500 meters, $18 \%$ in the range of 2 kilometers and $9 \%$ in the range of 10 kilometers. According to Corine Land Cover, it is observed that the daily rate of construction in this last band was more than 2 hectares per day from 1987 to 2005, going from 58,000 hectares to almost 72,000 in just 18 years.

On stretches of 2-10 kilometers of coastline, agriculture is one of the important variables of land transformation in the Spanish Mediterranean, and its 


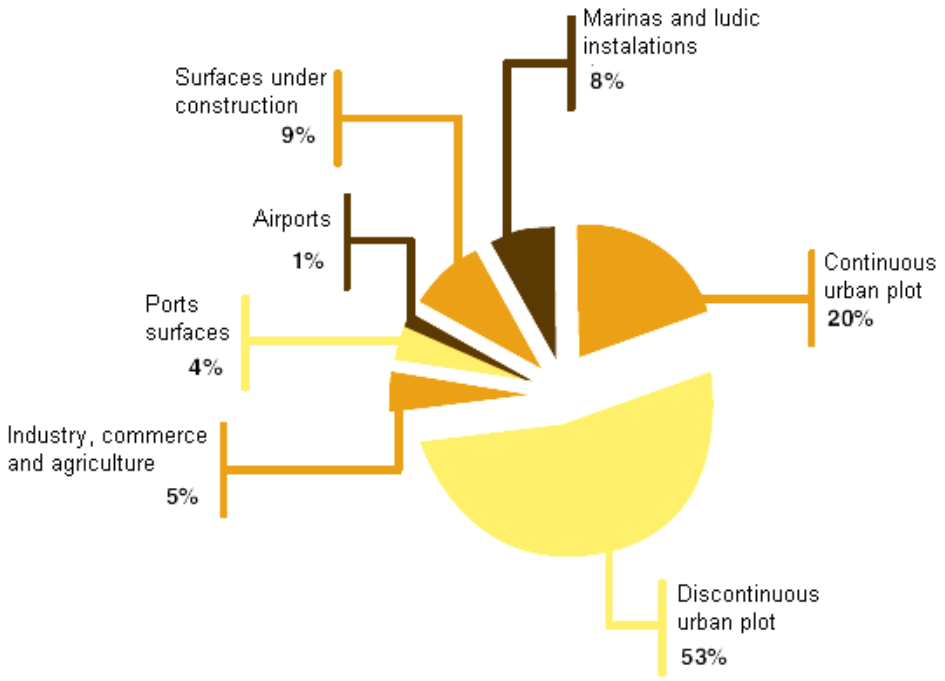

Figure 2: Land use in transformed areas of the Spanish coastline (source: [1]).

activity is closely linked to water availability. Due to weather conditions and the quality of the soil, many of the more than 4.5 million tons of vegetables, fruits and vegetables produced in Spain, are from the coastal areas. These activities are located especially in semi-arid areas, generating significant controversy about hydrologic planning and water transfers between regions.

Territorial policies in countries like Spain should be guided therefore by the control and planning of land and resources use. The transformation of land on the coastline is a phenomenon whose study requires long periods of analysis and an important data collection of multiple variables. In Spain, it also faces the usual problems of the administrative complexity involving the division of powers between administrations in order to assess territorial policies. This is, therefore, a productive field of research with many opportunities for innovation.

\section{Land transformation in the Mediterranean coast: from the tourist boom of the 60s to the real estate crisis of 2007}

If we analyze the above phenomenon of land consumption in the Mediterranean arc at a European level we can find some data demonstrating the need for retrospective studies. Apparently, the areas of greatest impact are currently at the French coast with consumed soil values above $50 \%$ in many of its coastal regions (Figure 3 [2]). 


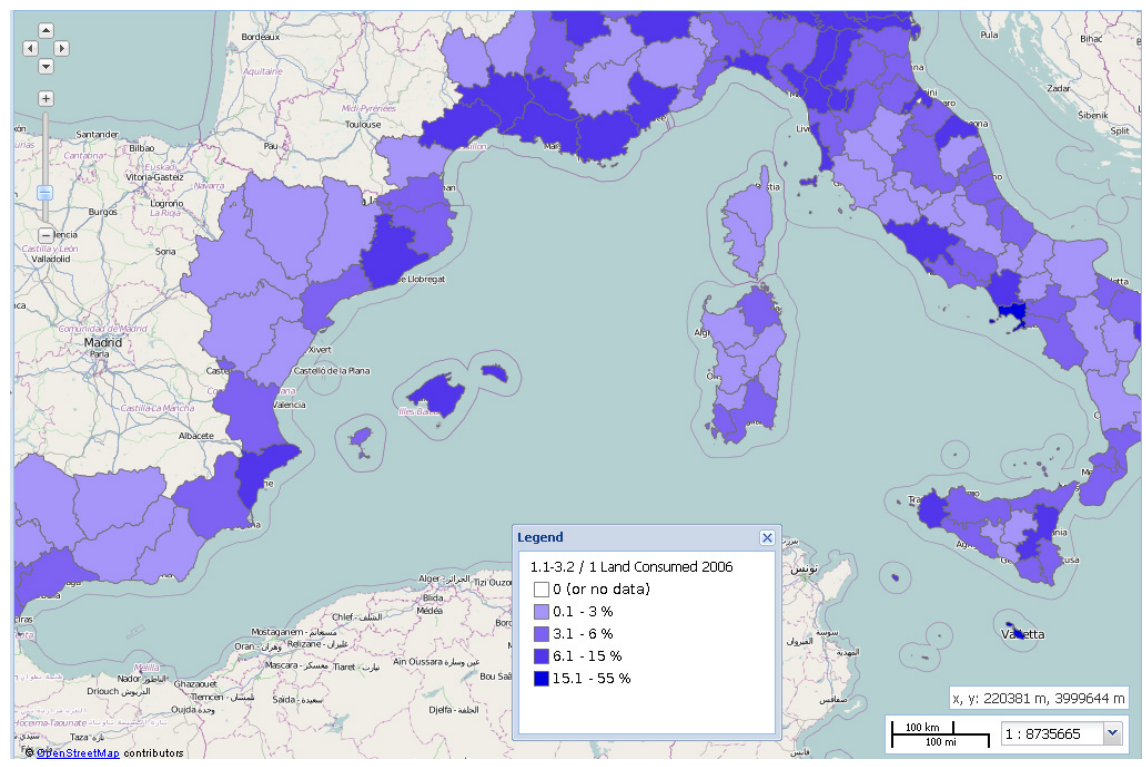

Figure 3: Land consumed in the Mediterranean arc until 2006 (source: Sdimed).

However, this impact does not mean currently greater vulnerability because it is the result of a long historic urbanization process for over 50 years. This land transformation process started in Europe in the 50s, mainly due to the appearance of mass tourism. If we analyze with recent periods we get very different results. It is in Spain in the range 1990-2000 (fig. 4) and 2000-2006 (Fig. 5) where it is produced the highest rates of annual growth in land consumption, with values of almost $10 \%$ in many regions.

Moreover, if we analyze the compared evolution between regions in the 1990-2000 and 2000-2006 bands we can see a certain pattern of "predator" behaviour in land consumption in the Spanish Mediterranean coastline. First, it can be observed a phenomenon of high intensity consumption in certain regions, which after reaching clear symptoms of exhaustion moves to other areas in the next time frame. This phenomenon of displacement in the intensity of land transformation can be surely extended to the entire 50-year time frame and is strongly linked to tourism and economic cycles.

The onset of this behaviour goes back on the Spanish coast to the creation in 1963 of the National Interest Tourist Centres and Areas law. This law is the first attempt to planning the territory in the Spanish coast and aims to create in a short time interval 900,000 foreign tourists places through the development of several tourist cities (Fig. 6).

Most of these places were located on the Mediterranean coast. The results of the plan were successful economically (while being Spain into recession in the 50s, the country had between 1964 and 1973 average growths of 7\% of GDP, tourism receipts amounting to 16,545 $\mathrm{M} \$$ and foreign investment of $5.047 \mathrm{M} \$$ ) 
but left in the territorial field a dangerous breeding ground for real state speculation [3].

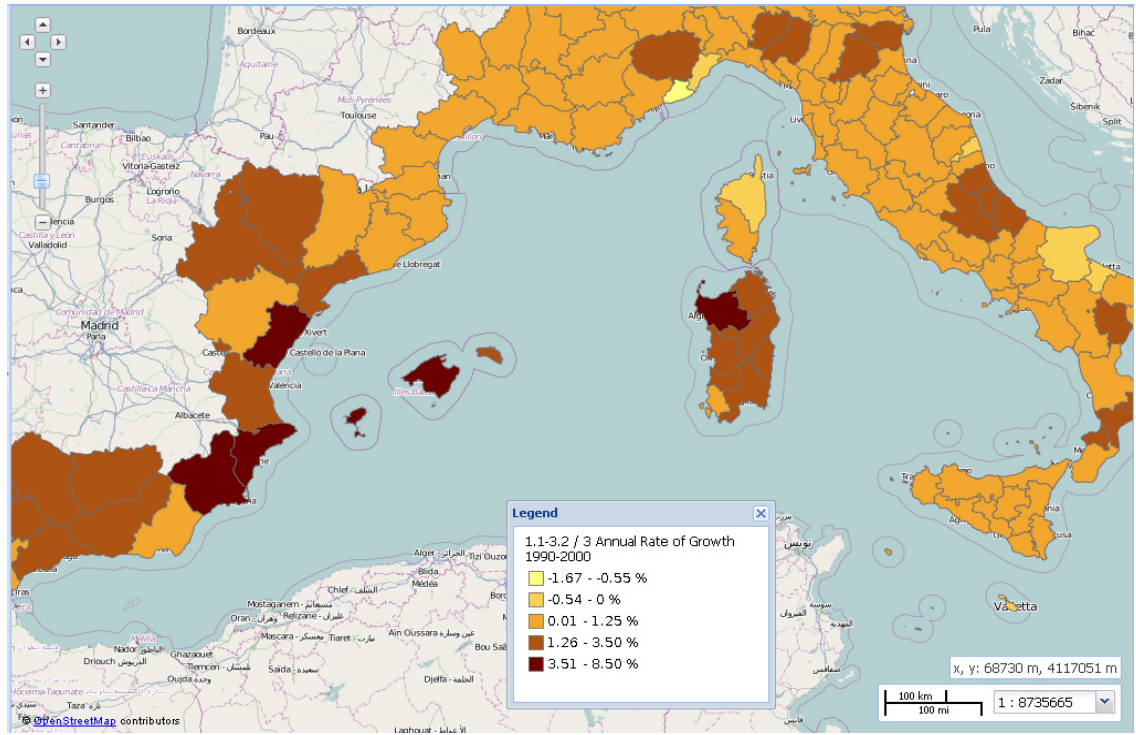

Figure 4: $\quad$ Annual rate of growth in 1990-2000 (source: Sdimed).

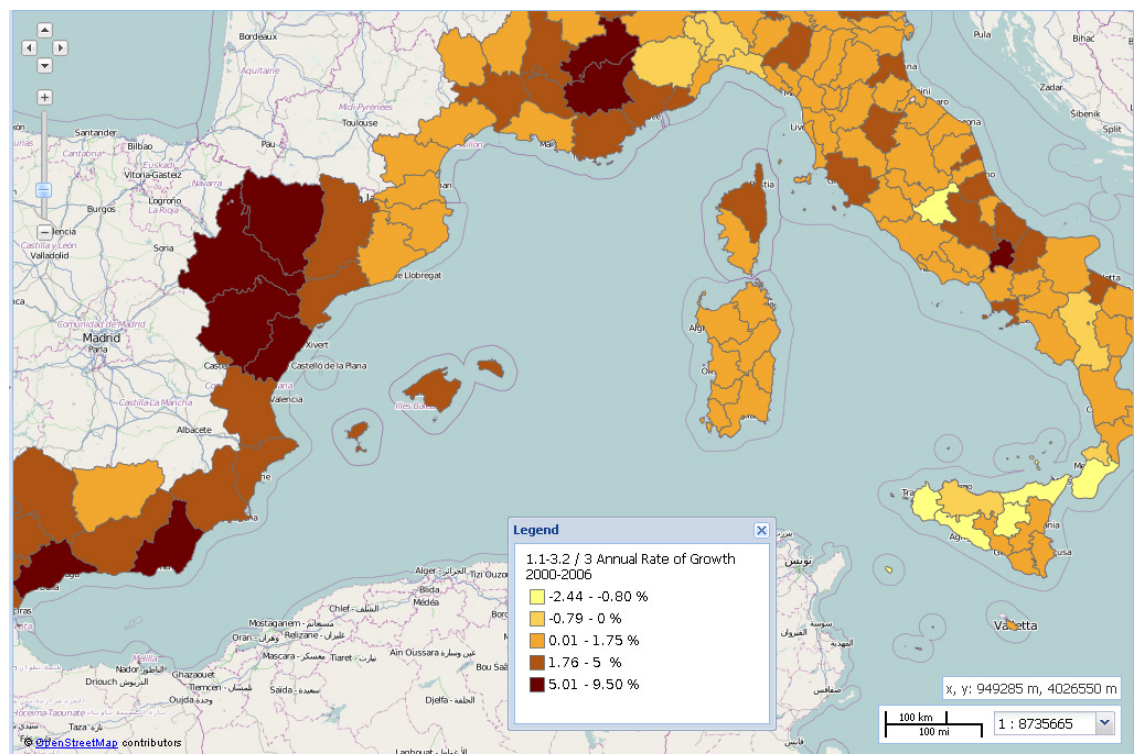

Figure 5: $\quad$ Annual rate of growth in 2000-2006 (source: Sdimed). 


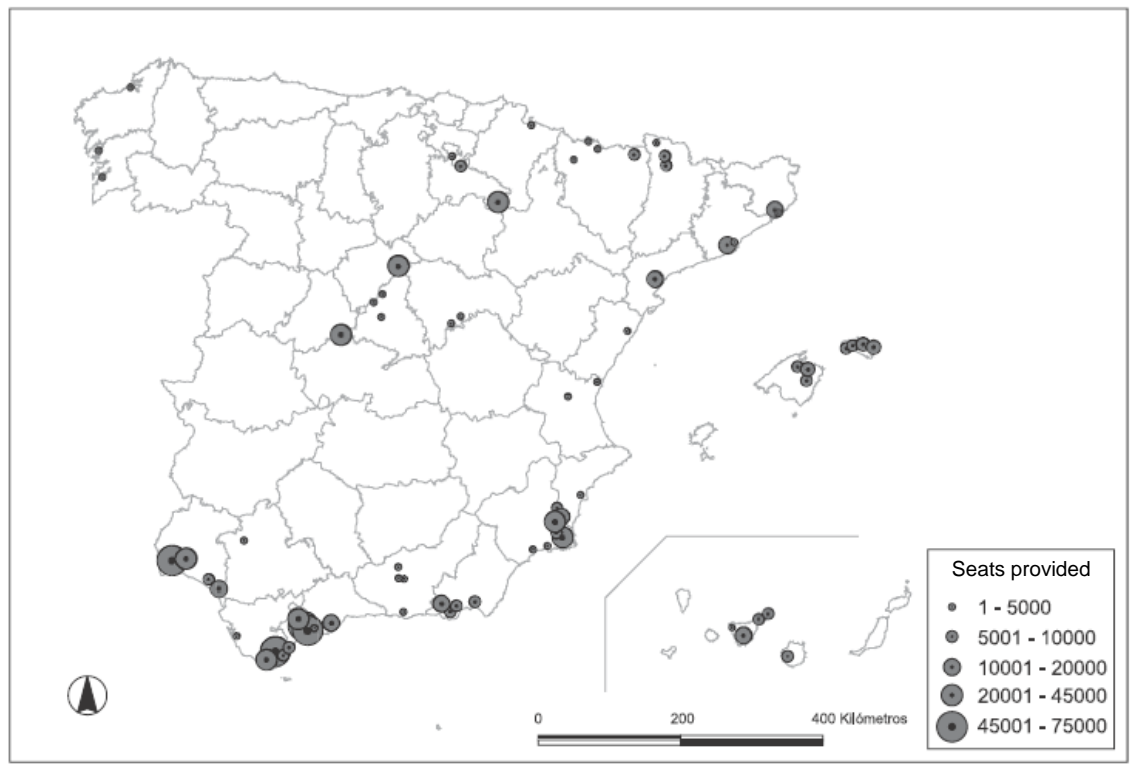

Figure 6: Distribution of seats provided by the 1963 Act (source: [3]).

The amount of urbanized land was not excessive in this period: 22,000 hectares between 1962 and 1975 against 200,000 of urbanized land in the period 1987-2000 or 52,000 of urbanized coast between 1987 and 2005 [3]. On the whole country (not only in coastal areas), between 1987 and 2005, the artificial surfaces increased from 669,222 hectares to 1,017,356, which represents an increase of 348134 hectares in total. That means an increase of 19,340 hectares per year of artificial surface.

Nevertheless, its impact was decisive in the economy and in the articulation of a new Spanish production model based on domestic consumption and heavily dependent on residential tourism and the service sector. This model encourages in a certain sense a continuous consumption of resources, particularly with regard to the soil as feedstock. This created a dangerous relationship between the construction sector, tourism (foreign, but mostly internal) and the service sector that needs of a continued use of coastal land to urbanize [4].

This behaviour is clearly reflected in the number of houses built in the last 20 years in Spain. The country went on to build more homes each year than France, Germany and Italy together over several years [5]. These homes were located primarily on the Mediterranean coast (Fig. 7) as second homes and are most of the housing stock that caused the financial crisis of Spanish banks in 2008.

This problem is increasingly complex to study because more and more variables are added each year to the equation model. Furthermore it is increasingly necessary to differentiate (as in the case shown in Figures 3, 4 and 5) cumulative behaviours from the inertial ones, or those that generate a new trend. For this, new tools of information and territorial analysis are proposed that 


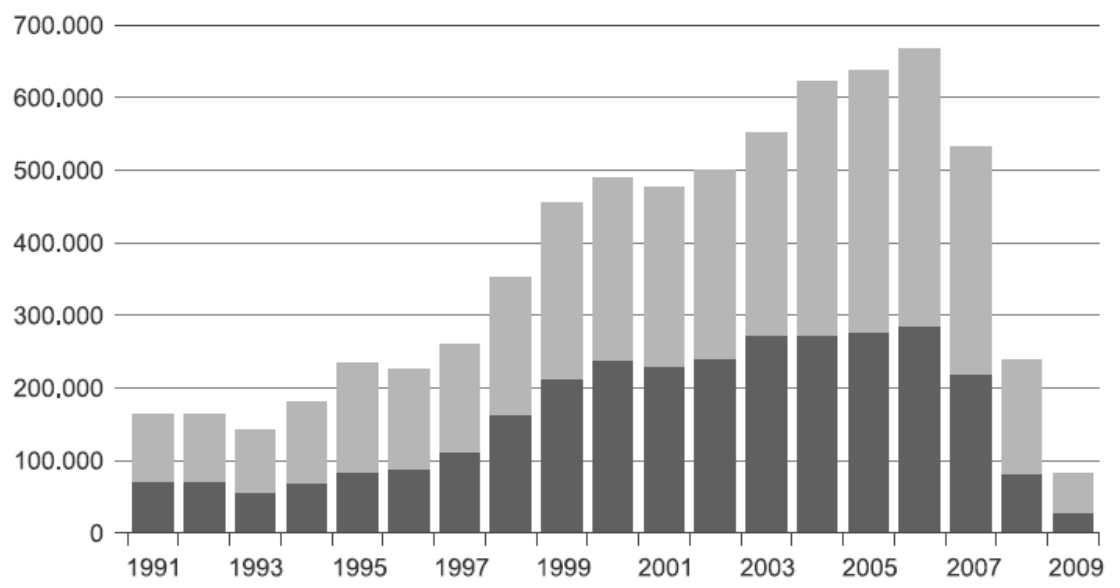

Figure 7: Number of houses finished each year in Spain (light) and Spanish Mediterranean coastal (dark) (source: [5]).

may be very interesting for future research based on retrospective spatial analysis.

\section{New research tools in territorial planning: GIS retrospective analysis}

Along the Spanish coast, on the fringe of the first 500 meters, are strung nearly 500 municipalities, belonging to 23 provinces and ten different regions. If we add the complex and heterogeneous distribution of powers between municipalities, regions and the state existing in Spain on diverse matters (coastal, urban planning, land use, infrastructures, environment, etc..), it is clear the need for tools and analysis systems more evolved in order to evaluate territorial policies. Behaviours such as land consumption in Figure 3 reveal many nuances if we include new variables of analysis or if we vary the study scale (Fig. 8).

In this field, the Region of Murcia, through the European research territorial projects Otremed (Tool for the Territorial Strategy of the Med Space) and OSDDT (Occupation des sols et developpement durable sur l'arc mediterranéen), has developed important territorial tools for analysis and advanced diagnostics in urban planning.

These tools, by using geo-referenced spatial information systems, allow implementing sophisticated analytical models that have already been successfully tested in some studies [3]. These systems can include an important number of variables and generate a modelling study deferred in time. On the basis of these tools and the studies initiated by Professor Steinitz [6], the methodology of retrospective spatial analysis is proposed. It consists of a land evaluation system that takes into account the evolution of the various parameters over extended periods of time to assess undertaken territorial policies and 


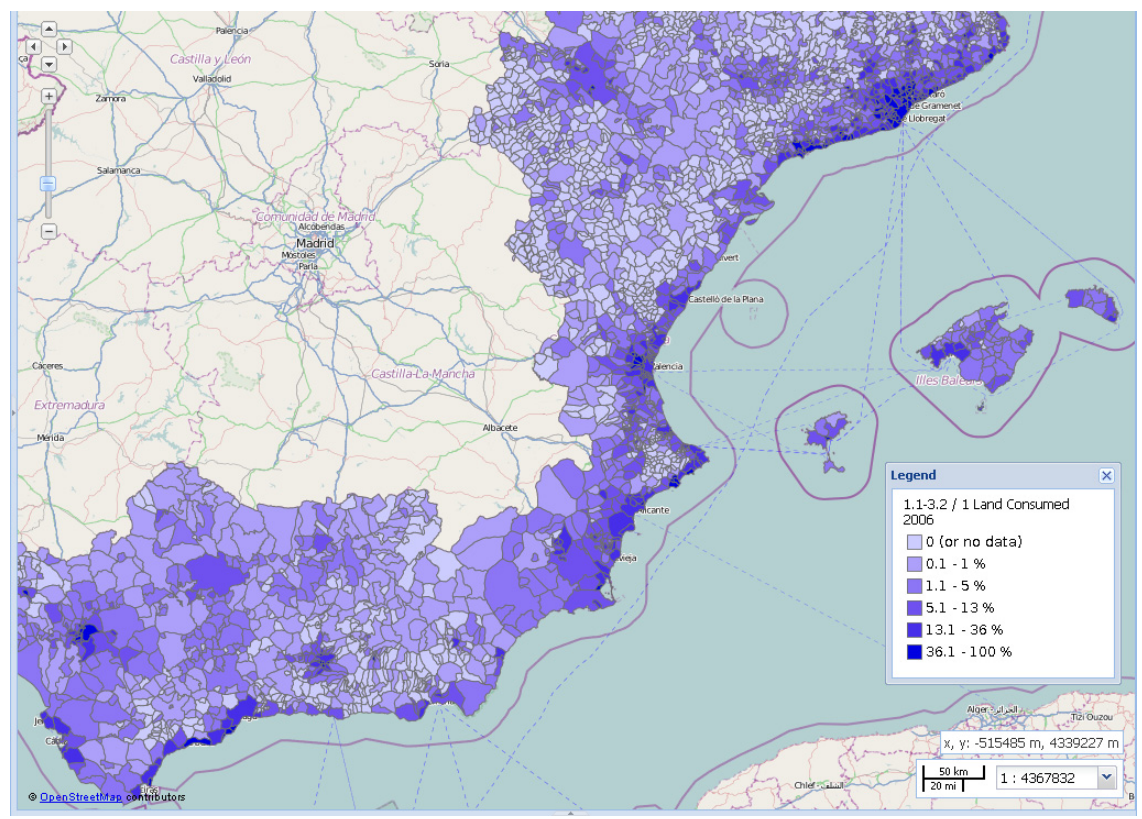

Figure 8: $\quad$ Land consumed in Spanish Mediterranean coast by municipalities until 2006 (source: Sdimed).

elaborate future diagnostics. This spatial analysis methodology is divided into four stages:

- A macrostructural analysis of the territory through tools like SDIMED;

- A "retrohistorical" detailed analysis of the study area with a tool like Cartomur;

- A functional analysis of a quantitative data collection with GIS georeferenced systems as Sitmurcia;

- A diagnosis of future with qualitative variables using a territorial evaluation system as IDERM.

\section{Example of application: Mazarron (Region of Murcia, south-eastern Spanish Mediterranean)}

To illustrate the proposed methodology we will perform a simple study of a stretch of coastline located in the south-eastern Spanish Mediterranean. It is located in the municipality of Mazarron in the Region of Murcia (Fig. 9).

If we make an analysis of the territorial structure with the Sdimed tool we can see that it is in theory a municipality with average values of accumulated land consumption (14\%), growth rates (3.4\%) and annual urban intensities (4.2\%) compared to the surrounding municipalities (Fig. 10). 


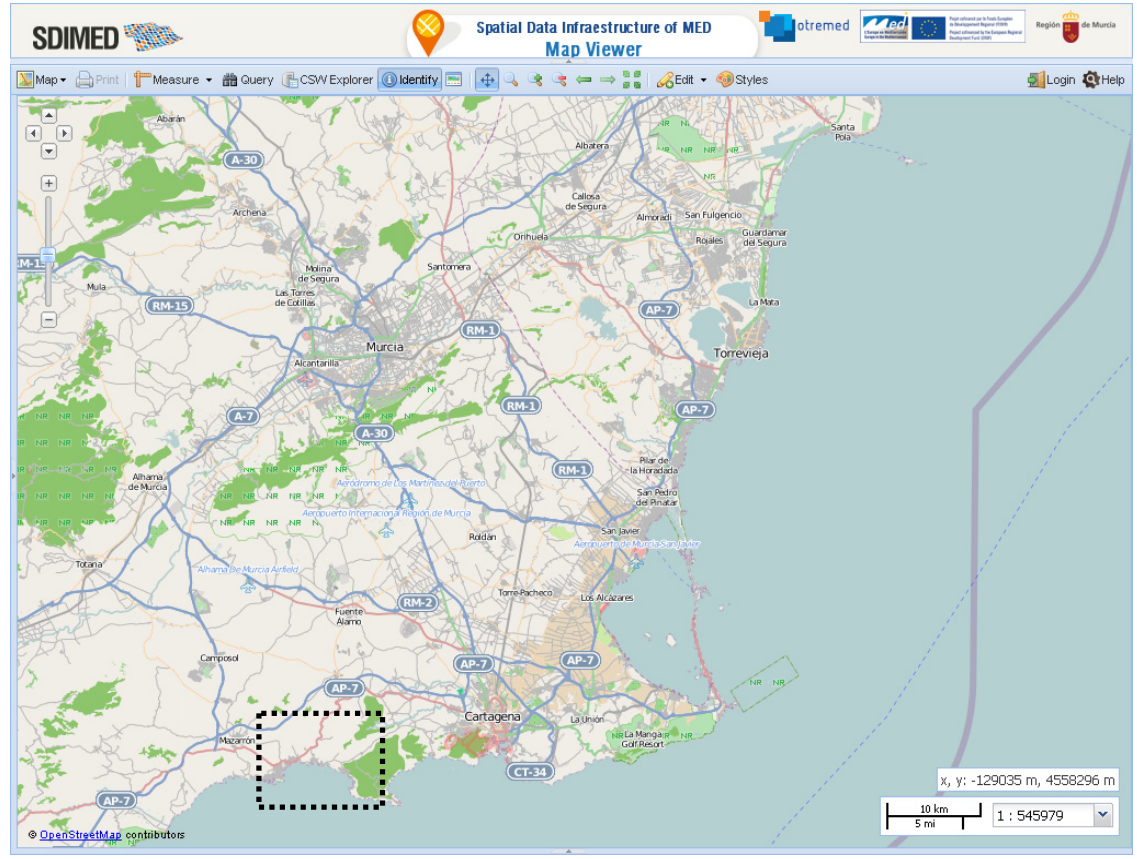

Figure 9: $\quad$ Territorial structure of the analyzed space (source: Sdimed).

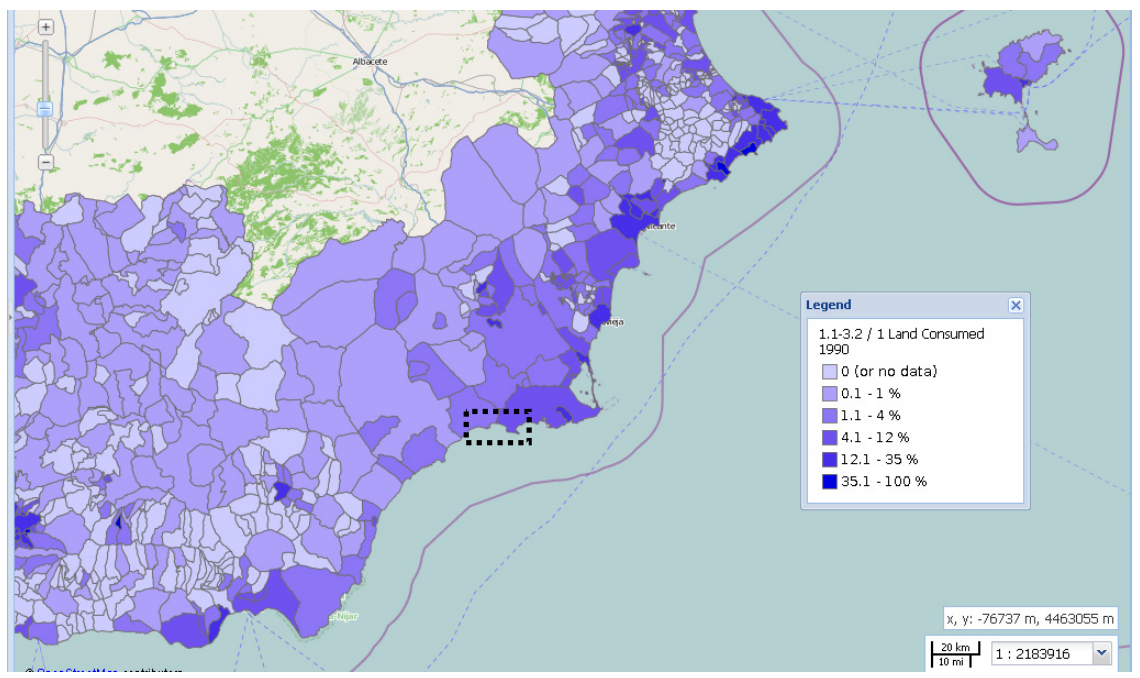

Figure 10: Land consumed in the Spanish south-eastern Mediterranean coast (source: [3]). 
A "retrohistorical" analysis of the past 50 years in the territory shows some interesting and unusual data. In the 50s there was a traditional urban core (called Mazarron) whose growth has stalled against the growth of a new discontinuous coastal city (called Puerto de Mazarron).This new satellite urban plot is starting since the 80s to expand into the entire coast accompanied by significant agricultural land transformations (Fig. 12).

In this coastal urban plot, we can obtain interesting data through georeferenced land information systems as Sitmurcia: urban planning, land use, the limitations imposed by environmental planning or infrastructure forecasts (Fig. 11).

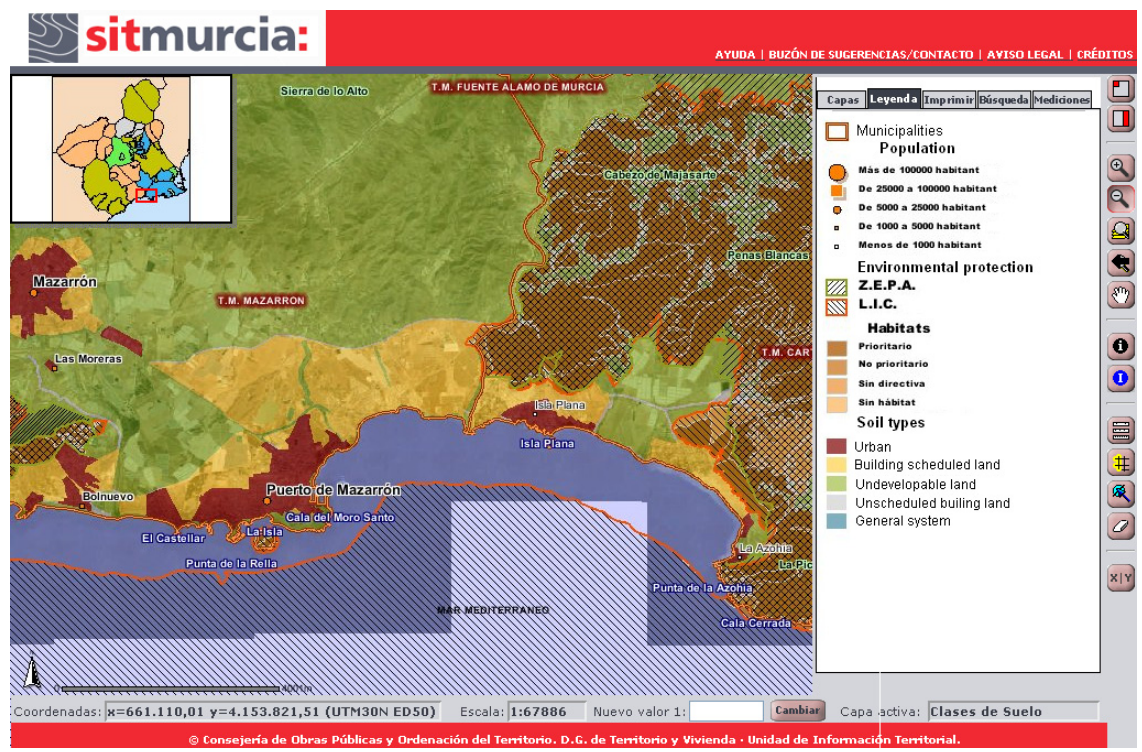

Figure 11: Overlapping of environmental limitations and urban planning (source: SitMurcia).

If we make an assessment with the program IDERM of urban planning forecasts taking into account all the variables, we can conclude that if all projects permitted by the City's General Plan were carried out with the current rate, the soil urban consumption and the transformed land surface would reach values of more than $41 \%$ and $62 \%$ in 2020 (Fig. 13). 


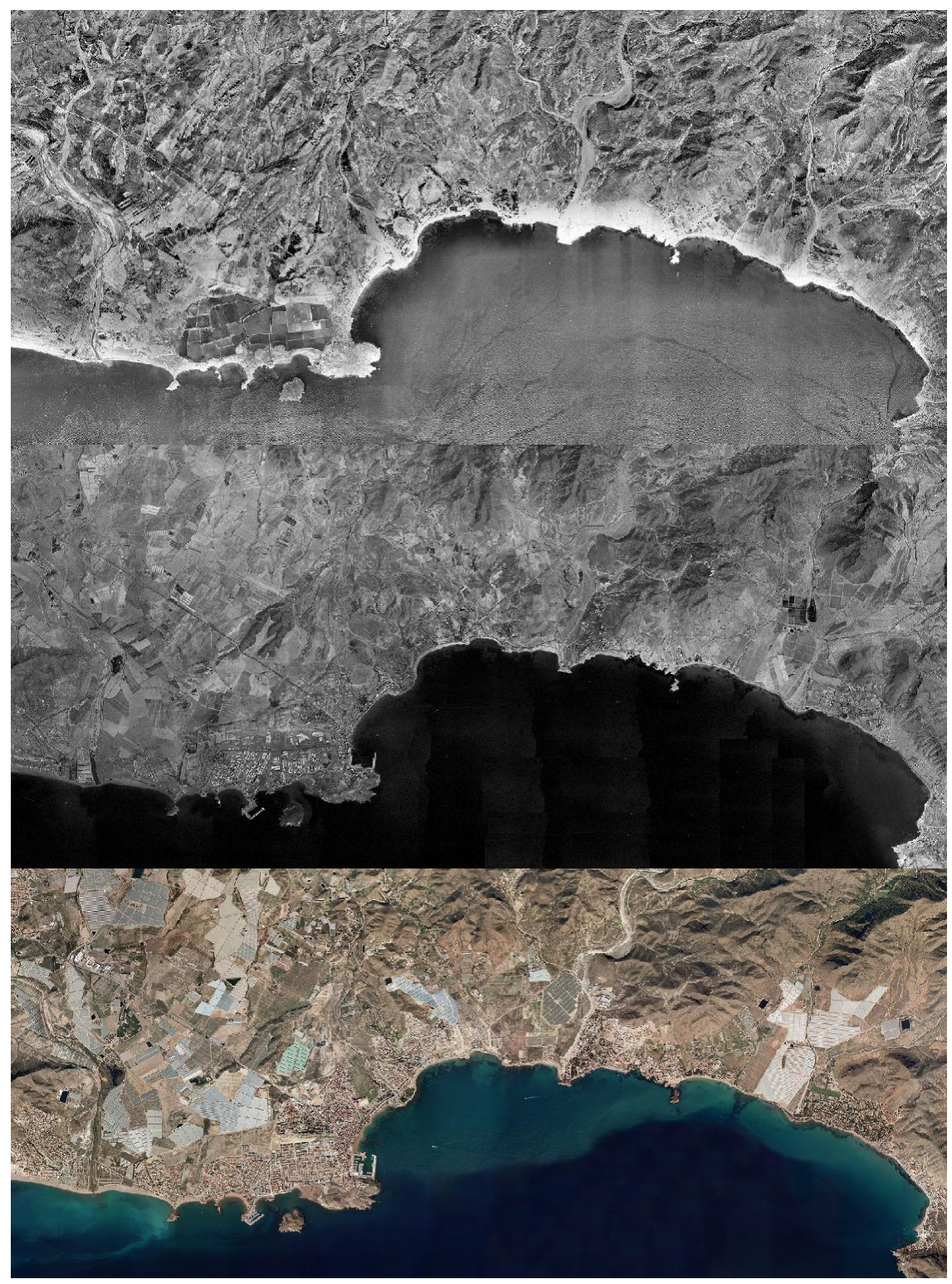

Figure 12: $\quad$ Territory evolution in 1956-1981-2007 (source: Cartomur). 


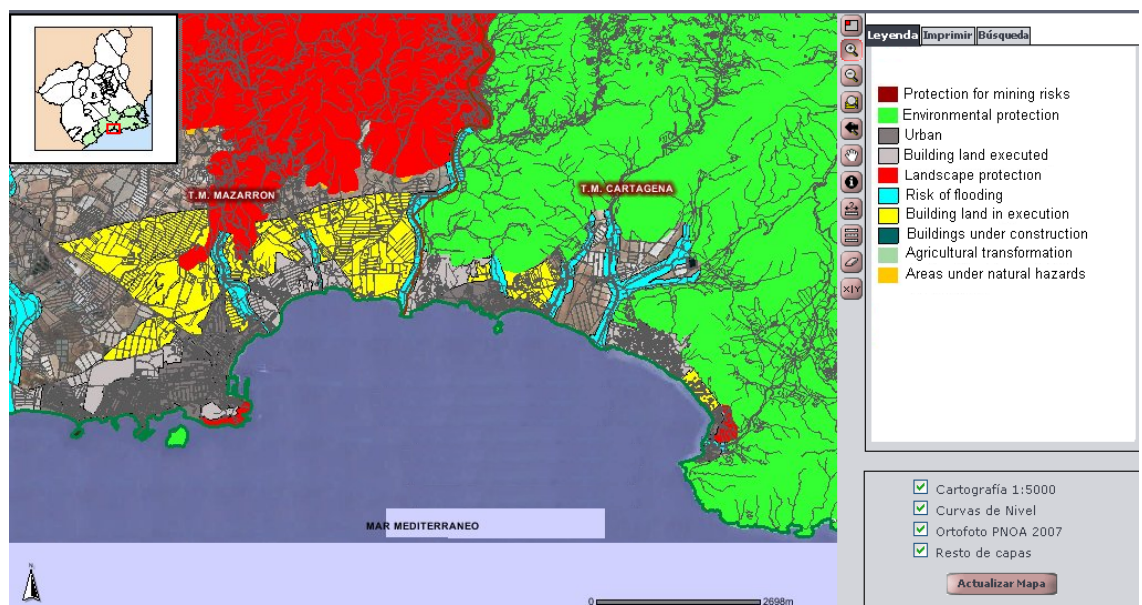

Figure 13: Analysis of urban planning forecasts (source: IDERM).

\section{Conclusions}

Spatial analysis should be a tool to correctly orient territorial policy towards sustainability. In this sense, territorial assessment models have become increasingly sophisticated because of the growing number of variables to be evaluated and the complex distribution of administrative powers.

In this field, the geo-referenced retrospective analysis is a future instrument to appraise all the variables needed to validate regional policies. This methodology allows achieving (in the present) diagnostics to detect future vulnerabilities undisclosed with the current indicators as in the case of Mazarron.

\section{References}

[1] Greenpeace. Destrucción a toda costa 2013, análisis a escala municipal. http://www.greenpeace.org/espana/es/reports

[2] European research projects in the Mediterranean space: Sdimed, Otremed y OSDDT. Program FEDER Interreg IV. www.sdimed.eu/ www.otremed.eu/ www.osdd.eu

[3] García-Ayllón S. En los procesos de urbanización del mediterráneo: el caso La Manga. PhD thesis, Polytechnic University of Valencia (Spain), 2013.

[4] Miralles i Garcia, J.L. Real estate crisis and sustainability in Spain. Proc of the Sustainable Development and Planning V, eds. C.A. Brebbia \& E. Beriatos, WIT Press: Southampton, pp. 123-133, 2011.

[5] Spanish National Statistics Institute. www.ine.es/inebmenu/mnu construc.htm

[6] Steinitz, C. Environmental Planning for Communities. Technology Transfer and Support Division, Office of Research and Development, United States Environmental Protection Agency: Cincinnati, Ohio, 2000. 